$9 \quad{ }^{1}$ Plant Science Laboratory, Cranfield University, Bedfordshire, MK43 0AL, UK

\section{Effect of deficit irrigation and methyl jasmonate application on the composition of strawberry (Fragaria $\mathrm{x}$ ananassa) fruit and leaves}

\author{
Jordi Giné-Bordonaba ${ }^{1}$ and Leon A. Terry*
}

${ }^{2}$ Present address: Institute for Food and Agricultural Research and Technology (IRTA),

Postharvest Programme, Parc Científic i Tecnologic Agroalimentari de Lleida, Parc de

Gardeny, Lleida, 25003, Spain.

*Corresponding author. Tel.: +44-7500 766490; Fax: +44-1234 758380.

E-mail address: 1.a.terry@ cranfield.ac.uk (L.A. Terry). 
Drought stress is among the most severe environmental risks threatening strawberry 25 production. In the present study, the effect of deficit irrigation (DI; $50 \mathrm{~mL} /$ day) and/or 26 elicitation with methyl jasmonate (MeJA; $0.1 \mathrm{mM})$ on the composition of secondary fruit and 27 leaves from three strawberry pre-commercial cultivars (253/29, 279/4 and 279/5) was 28 investigated and compared to plants kept at or near field capacity (200 mL/day). For certain 29 cultivars (253/29), DI applied at green stage of fruit development resulted in a considerable 30 reduction in berry size (1.7-fold). In other cultivars (279/4 and 279/5), fruit size was 31 comparable in DI-treated and fully irrigated plants. Changes in the major sugars and organic 32 acids of strawberry leaves and fruit were cultivar and organ dependent and were associated to 33 an osmotic adjustment strategy within the plant to counteract the effects of drought. Overall, 34 elicitation with MeJA had a minimal effect on plant growth and morphological traits. 35 Nevertheless, MeJA increased fructose content of DI-treated leaves and palliated the 36 differences in glucose content of fruit from different water treatments. The most pronounced 37 effect of MeJA was related to an enchanced synthesis and accumulation of pelargonidin-338 glucoside (nearly 2-fold) in red-ripe fruit from cultivar 279/5.

41 Keywords: anthocyanins, berry size, drought, organic acids, sugars. 


\section{Introduction}

47 Berries have long been recognised to play an important role in human nutrition, providing

48 health-benefits against a wide range of diseases, mainly due to their elevated content in

49 certain bioactives including ascorbate, anthocyanins, phenolic acids, carotenoids, etc. (Giné

50 Bordonaba and Terry, 2011a; Manganaris et al., 2013). Most bioactive compounds within the

51 plants are secondary metabolites whose synthesis can be triggered in response to biotic and

52 abiotic stresses, such as UV radiation, drought, wounding as well as infections (Terry and

53 Joyce, 2004; Terry et al., 2007a; Jahangir et al., 2009). In the particular case of strawberries,

54 several studies have demonstrated the effect that certain preharvest treatments or cultivation

55 practices have on strawberry fruit biochemistry (Terry et al., 2007a; Keutgen and Pawelzik,

56 2008; Crespo et al., 2010; Giné Bordonaba and Terry, 2010), including the effect on the

57 concentration of certain taste- and health-related compounds. For instance, earlier works

58 demonstrated that besides the positive environmental effects (i.e. water savings), deficit

59 irrigation (DI) in strawberry plants resulted in berries with higher concentrations of

60 anthocyanins and antioxidant capacity (Terry et al., 2007a) as well as other markers of

61 strawberry fruit quality. Later studies revealed that such effects were cultivar dependent (Giné

62 Bordonaba and Terry, 2010). Nonetheless, DI applied to strawberry plants has been linked

63 with a significant reduction in fruit size and yield (Blatt, 1984; Serrano et al., 1992; Krüger et

64 al., 1999; Liu et al., 2007; Terry et al., 2007a) which also seems to be cultivar dependent

65 (Giné Bordonaba and Terry, 2010).

66 Jasmonic acid (JA) and its methyl ester methyl jasmonate (MeJA) are naturally occurring

67 plant hormones which have been shown to regulate a wide range of physiological and

68 biological processes (Cheong and Choi, 2003; Rohwer and Erwin, 2008), including responses

69 to drought stress. Given the capacity of MeJA to act as an elicitor and considering that this 

compound is already classified as Generally Recognise As Safe (GRAS) substance by the

71 U.S. Food and Drug Administration (Wang et al., 2009) it may have a potential for enhancing

72 the synthesis of bioactive compounds (Perez-Balibrea et al., 2011) and increase fruit quality

73 whilst palliating the negative effects of DI. In this context, Wang (1999) reported that 74 preharvest application of MeJA (0.01-0.1 mM) resulted in changes in plant metabolism that 75 rendered strawberry leaves to better withstand in vitro water stress. Preharvest application of 76 MeJA seems to alter stomatal opening in strawberry (Wang, 1999) and other crops (Horton, 77 1991) resulting in better transpiration control and hence potentially improving water stress 78 tolerance. In soybean, MeJA has been shown to ameliorate the damaging effects of drought 79 stress by modifying endogenous phytohormones and polyamines (Hassanein et al., 2009). 80 Moreover, both preharvest and postharvest application of MeJA has been associated with 81 greater antioxidant capacity in Chinese red bayberry (Wang et al., 2009) and strawberry 82 (Ayala-Zavala et al., 2005) as well as enhanced anthocyanin synthesis in apples (Rudell and 83 Mattheis, 2008) or other berries (Wang, 2003; Wang et al., 2008).

84 This study was conducted to further understand the response mechanisms of strawberry plants 85 to water stress conditions and to elucidate whether or not elicitation with MeJA may be a 86 suitable alternative to minimise the negative effects of DI on berry weight of three different 87 pre-commercial strawberry cultivars whilst maintaining/enhancing the taste- and health88 related composition of the fruit. Special attention was given to quantifying sugar and organic 89 acids in both fruit and leaves as major respiratory substrates, and anthocyanins and ascorbic 90 acid concentrations in fruit. 


\section{Materials and methods}

94

\subsection{Plant materials and experimental design}

Three different maiden year cold-stored strawberry pre-commercial cultivars (viz. 253/29, 279/4 and 279/5) were supplied by Redeva (Surrey, UK) and grown in a glasshouse (April to July) in $1 \mathrm{~L}$ capacity pots containing commercial standard compost. Cultivars were selected by Redeva breeders to assess their potential adaptation to dry climates and drought. A completely randomised design was adopted considering cultivar, water treatments (50 or 200 $\mathrm{ml}$ day $^{-1}$ ) and MeJA treatments (none or $0.1 \mathrm{mM}$ ) as the principal sources of variation. Prior to commencing water treatments plants were kept at or near field capacity $\left(c a .0 .7 \mathrm{~m}^{3}\right.$ of water per $\mathrm{m}^{3}$ of soil; conductivity ca. $850 \mathrm{mV}$ ) for approximately three weeks following the methodology described in earlier works (Terry et al., 2007a; Giné Bordonaba and Terry, 2010). Water treatments started once the majority of primary fruit from the primary truss were at green I stage of development (prior to the second fruit expansion growth phase; Terry et al., 2004). Then, plants were irrigated daily (ca. 09:00 h) with either 50 or $200 \mathrm{ml} \mathrm{day}^{-1}$ over an eight-week period. Methyl jasmonate (Sigma, Dorset, UK) treatments at $0.1 \mathrm{mM}+0.05 \%$ Tween-20 (Wang, 1999) were applied as a foliar spray to incipient runoff every 72h. MeJA treatments started when the majority of the primary fruit from the primary truss were at white stage of development. Similarly, control plants were sprayed with a $0.05 \%$ Tween-20 solution.

\subsection{Soil moisture content and environmental monitoring}

Soil moisture content, recorded as the conductivity from the growing media $(\mathrm{mV})$, was measured daily $(c a .16 .00 \mathrm{~h})$ by time-domain-reflectometry (TDR) using a Thetaprobe (ThetaKit type TK3, Delta-T devices, Cambs., UK). Hourly temperatures within the 
glasshouse were recorded by means of a Tiny Tag Ultra 2 data logger (Gemini Data Logger,

117 Sussex, UK), shielded from solar radiation. Mean temperature inside the glasshouse through 118 the growing period was $21^{\circ} \mathrm{C}$.

\subsection{Fruit, leaf and runner sampling}

From each plant, all fruit from the primary truss were harvested at red stage. Four fully expanded leaves of similar size and age per plant were excised towards the end of the trial (30

122 days after initiation of water treatments and when all experimental fruit had been harvested)

123 and the length and surface area of the leave recorded. On the last day of the experiment, 124 following leaf sampling, the length as well as the total runner density ( $\mathrm{g}$ ) was determined for 125 each plant. After harvest or excision, objective colour of fruit and leaves was measured using 126 a Minolta CR-400 colorimeter and a DP-400 data processor (Minolta Co. Ltd., Japan) with an $1278 \mathrm{~mm}$ light-path aperture, respectively (Terry et al., 2007b). Berry and leave weight was 128 measured and recorded and thereafter immediately snap-frozen in liquid nitrogen and stored 129 briefly at $-40^{\circ} \mathrm{C}$ before being freeze-dried in an Edwards Modulyo freeze drier (W. Sussex, $130 \mathrm{UK}$ ) for 6 and 4 days at $0.015 \mathrm{kPa}$, respectively. Lyophilized samples were subsequently 131 ground in a pestle and mortar, weighed and returned to the freezer until use. All reagents 132 were purchased from Sigma (Dorset, UK) unless otherwise stated.

\subsection{Extraction and quantification of sugars and organic acids}

Sugars from both freeze-dried berries and leaves were extracted using $62.5 \%(\mathrm{v} / \mathrm{v})$ aqueous methanol as described elsewhere (Terry et al. 2007a). Sugar content was determined using an Agilent 1200 series HPLC binary pump system (Agilent, Berks., UK), equipped with

137 an Agilent refractive index detector (RID) G1362A. Strawberry extracts $(20 \mu \mathrm{L})$ were diluted 
139 mm diameter (Phenomenex, CA, USA; Part no. 00H-0130-K0) with a Carbo-Ca ${ }^{2+}$ guard 140 column of $4 \mathrm{~mm}$ x $3 \mathrm{~mm}$ diameter (Phenomenex,; Part no. AJ0-4493). Column and oven 141 temperature as well as the mobile phase conditions were those reported earlier (Giné 142 Bordonaba and Terry, 2010). Extracts for organic acids determination were prepared as 143 described elsewhere from both berry or leave freeze-dried samples (Giné Bordonaba and 144 Terry, 2010). L-ascorbic, citric, and malic acid contents in extracts were detected at $210 \mathrm{~nm}$ 145 using the same HPLC system as described above equipped with an Agilent DAD $146 \mathrm{G} 1315 \mathrm{~B} / \mathrm{G} 1365 \mathrm{~B}$ photodiode array with multiple wavelength detector. The mobile phase (1.0 $147 \mathrm{~mL} \min ^{-1}$ ) was analytical grade degassed $0.2 \%(\mathrm{w} / \mathrm{v})$ metaphosphoric acid in $\mathrm{H}_{2} \mathrm{O}$ (Giné 148 Bordonaba and Terry, 2009). The presence and abundance of individual sugars or organic 149 acids were automatically calculated by comparing sample peak area to standards $(0.025-2.5$ $150 \mathrm{mg} \mathrm{mL}{ }^{-1}$ ) using ChemStation Rev. B.02.01.

\section{$151 \quad 2.5$ Antioxidant capacity of strawberry leaves}

Antioxidant capacity from strawberry leaves was measured using the FRAP assay as 153 described in earlier works (Terry et al., 2007a; Giné Bordonaba and Terry, 2012) with some 154 modifications. A $50 \mu \mathrm{L}$ aliquot of diluted sample extract $(1: 9 ; \mathrm{v} / \mathrm{v})$ or $\mathrm{Fe}^{2+}\left(\mathrm{FeSO}_{4} \cdot 7 \mathrm{H}_{2} 0\right)$ 155 standards $(0-5.0 \mathrm{mM})$ was added to $3.6 \mathrm{~mL}$ of freshly prepared FRAP working solution (viz. $1565 \mathrm{~mL}$ of $10 \mathrm{mM}$ TPTZ (2,4,6-tripyridyl-2-triazine) in $40 \mathrm{mM} \mathrm{HCl}+5 \mathrm{~mL}$ of $10 \mathrm{mM} \mathrm{FeCl}_{3}$ 157 in $50 \mathrm{~mL}$ of $300 \mathrm{mM}$ acetate buffer). The reaction mixture was incubated at $37^{\circ} \mathrm{C}$ for $10 \mathrm{~min}$ 158 and absorbance measured spectrophotometrically at $593 \mathrm{~nm}$ using a Camspec M501 UV/Vis 159 spectrophotometer. Antioxidant capacity was expressed as the concentration of antioxidants 160 having a ferric reducing ability (mmols $\left.\mathrm{Fe}^{2+} \mathrm{g}^{-1} \mathrm{DW}\right)$. 


\subsection{Analysis of individual anthocyanins}

Individual anthocyanins were extracted using the methodology described in earlier

163 works (Giné Bordonaba and Terry, 2011b) by mixing $150 \mathrm{mg}$ of freeze-dried fruit sample

164 with $3 \mathrm{ml}$ of $70 \%(\mathrm{v} / \mathrm{v})$ methanol and $0.5 \%(\mathrm{v} / \mathrm{v}) \mathrm{HCl}$ in HPLC-grade water. The slurry

165 obtained was held at $35^{\circ} \mathrm{C}$ in a water bath with constant shaking for $1.5 \mathrm{~h}$; mixing the samples

166 every $15 \mathrm{~min}$. Finally, the flocculate obtained was filtered through a $0.2 \mu \mathrm{m} \mathrm{Millex-GV}$

167 syringe driven filter unit (Millipore Corporation, MA) and the clear extract analyzed by 168 HPLC coupled to a Diode Array Detector (DAD), using the same equipment as described for 169 sugars and organic acids. The anthocyanin profile of strawberry fruit was determined 170 according to the method described by Gine Bordonaba et al. (2011).

\section{$171 \quad 2.7$ Data analysis}

172 All statistical analysis were carried out using Genstat for Windows, Version 10 (VSN 173 International Ltd., Herts., UK). Data were subjected to analysis of variance (ANOVA) tests 174 based on a completely randomised design. Least significant difference values (LSD; $P=0.05)$ 175 were calculated for mean separation using critical values of $\mathrm{t}$ for two-tailed tests. 
182

183

184

185

186

187

188

189

190

191

192

193

194

195

196

197

198

199

200

201

202

203

204

\subsection{Morphological and physiological changes in response to drought or elicitation}

In agreement with earlier works (Terry et al., 2007a; Giné Bordonaba and Terry, 2009; Grant et al., 2010) soil water content differed between treatments but also between cultivars according to the water stress conditions (Figure 1). In all cultivars, deficit irrigation resulted, in average, in 2-fold lower water content in the growing media if compared to fully irrigated plants. Soil water content for DI-treated plants declined following similar water-soil dynamics to that previously reported (Liu et al., 2007; Terry et al., 2007a; Savić et al., 2008; Giné Bordonaba and Terry, 2010; Grant et al., 2010). This said, greater differences between normal $\left(200 \mathrm{~mL} \mathrm{day}^{-1}\right)$ or deficit $\left(50 \mathrm{~mL} \mathrm{day}^{-1}\right)$ irrigated plants where encountered for cultivar 253/29 (less drought-tolerant cultivar; Figure 1). Accompanying the observed changes in plant water uptake, changes in berry weight of secondary strawberry fruit, from the primary truss, in response to different irrigation conditions were cultivar depended and therefore in agreement with earlier findings from Giné Bordonaba and Terry (2010) and Grant et al. (2010, 2012). Whereas no significant changes were observed in fruit weight of cvs. 279/4 and 279/5 subjected or not to DI conditions, cv. 253/29 held under drought conditions produced nearly 1.7-fold smaller fruit (Figure 2). This result together with the observed soil water conductivity values suggest that both cvs. 279/4 and 279/5 were more drought-tolerant than cv. 253/29.In comparison with other studies (Liu et al., 2007; Terry et al., 2007a; Savić et al., 2008; Giné Bordonaba and Terry, 2010) the lesser reduction of berry weight in fruit from cvs. 279/4 and 279/5 grown under DI conditions may be related to not only the capacity of these cultivars to better withstand water stress conditions but also may be associated to initiating water stress at later fruit developmental stages (i.e. green stage instead of flower initiation as reported earlier (Terry et al., 2007a; Giné Bordonaba and Terry, 2010)). 
In contrast to the clear effect of water treatments on soil water content, plants from different 206 cultivars responded differently to foliar treatment with MeJA. Whereas preharvest application 207 of MeJA did not have an effect on the amount of water extracted from the growing media in 208 cv. 253/29, 1.5-fold lower soil water content was observed in MeJA-treated plants from cv. 209 279/4, regardless of the irrigation treatment (Figure 1). In cultivar 279/5, MeJA increased 210 (1.6-fold) and reduced (1.2-fold) soil water content for DI-treated and non-water stressed 211 plants, respectively. Differences in the amount of water extracted by the plant from the 212 growing media may be related to the direct effect of MeJA on root growth (Staswick et al., 213 1992), which seems to be cultivar dependent, as well as a direct effect on root hydraulic 214 conductivity (Savić et al., 2008). For instance, in Arabidopsis thaliana, primary root growth 215 was inhibited by $50 \%$ when seedlings were grown on medium containing MeJA (Staswick et 216 al., 1992). Accordingly, visual inspection of root development at the end of the trial for each 217 plant indicated a positive correlation between the capacity of the plant to extract water and 218 root growth (data not shown) but supported only partially the associations between MeJA and 219 root development found by others (Staswick et al., 1992; Maksymiec and Krupa, 2007). 220 Differences between this and early studies may also be the result of the different species being 221 investigated as well as different methodologies used in the application of MeJA. In addition,

222 in the present study, MeJA was applied at an advanced fruit phenological stage when most of 223 the root development has already occurred. Elicitation with MeJA had a minimal effect on 224 berry weight and was cultivar dependent. In fruit from cv. 279/4 treatment with MeJA 225 resulted in a slight reduction of fruit weight regardless of the water treatment whereas no 226 effect was noticed in fruit from the rest of cultivars (Figure 2).

227 Fruit dry matter as a proportion of fresh weight was not significantly affected by the 228 conditions imposed in this study (Figure 2). In contrast, earlier works have shown that DI 
229 applied at earlier fruit developmental stages resulted in fruit with greater dry matter content

230 (Serrano et al., 1992; Krüger et al., 1999; Liu et al., 2007; Terry et al., 2007a; Giné Bordonaba

231 and Terry, 2010). Dry matter content from leaves was neither affected by water treatments

232 and hence it may be plausible to speculate that the concentration effect reported in earlier

233 works (Terry et al., 2007a; Giné Bordonaba and Terry, 2010) is likely to have been related to

234 the limitation of water uptake from the plants rather than to an enhanced import of solutes into

235 the fruit from other parts of the plant (i.e. leaves).

236 As expected, greater water supplied to the plant resulted in greater runner biomass in all

237 except in plants from the less drought-tolerant cv. 253/29. Accordingly, it is well accepted

238 that greater water supply to strawberry plants generally resulted in higher vegetative growth,

239 including runners fresh mass (Grant et al., 2010 and 2012). No other morphological traits

240 (leaves length, foliar density) except some differences in objective colour of leaves were 241 altered by the different treatments applied (data not shown).

\section{$242 \quad 3.2$ Leaf biochemical changes}

243 Fructose content of leaves was significantly different between cultivars, water

244 treatments and the interaction between water treatments and MeJA (Table 1). Excised leaves

245 from cultivar 279/5 had the greatest fructose content $\left(20.26 \mathrm{mg} \mathrm{g}^{-1} \mathrm{FW}\right)$ followed by cv. $279 / 4$

246 (15.41 $\left.\mathrm{mg} \mathrm{g}^{-1} \mathrm{FW}\right)$ and cv. 253/29 (13.24 $\left.\mathrm{mg} \mathrm{g}^{-1} \mathrm{FW}\right)$ and regardless of the water treatments.

247 Under DI conditions, leaves had on average, 1.2-fold greater fructose content than leaves 248 from plants kept at or near field capacity. Similar trends were observed for glucose and hence

249 these results suggest that hexose sugars accumulate in response to drought as also reported for 250 tomato plants submitted to other abiotic stress (Khelil et al., 2007). This specific behaviour 251 may represent a beneficial plant response by avoiding metabolic inhibitions while 
252 concomitantly contributing to an osmotic adjustment (solute potential) within the plant 253 (Balibrea et al., 2000). Elicitation with MeJA in combination with DI resulted in all cases in 254 higher glucose content as compared to non-elicitated plants (Table 1). Nor sucrose or the total 255 sugar content was affected by the conditions imposed in this study rather than genotypic 256 differences. AsA concentrations were significantly different between cultivars, irrigation 257 regimes but were not affected by MeJA. Specifically, AsA was greater in leaves from plants 258 grown under reduced irrigation $\left(1.53 \mathrm{mg} \mathrm{g}^{-1} \mathrm{DW}\right)$ as compared to plants kept at or near field 259 capacity $\left(1.15 \mathrm{mg} \mathrm{g}^{-1} \mathrm{DW}\right)$. Greater AsA content in DI-treated leaves may be a plant defence 260 strategy to scavenge hydroxyl radicals and detoxify the accumulation of $\mathrm{H}_{2} \mathrm{O}_{2}$ resulting from 261 water stress. The greatest increase (2-fold) in AsA as a result of drought was observed in 262 leaves from cv. 279/5. Contrasting results were found by Wang et al (1999) where leaves of 263 drought-stressed strawberry plants had lower AsA content if compared to leaves from control 264 plants. However, different cultivars and experimental conditions were tested in each study. 265 Malic acid content in leaves was affected by the interaction between water treatments and 266 genotypes. Except for cv. 279/5, where malic acid was lower (1.7-fold) in leaves from DI267 treated plants, reduced water resulted in greater (1.15-fold in average) amounts of malic acid 268 in leaves from cultivars $279 / 4$ and 253/29. Increased malic acid content in leaves, as also 269 observed for certain sugars, may result from lowered respiration and hence confirm the 270 osmotic adjustment (solute potential) strategies within different plant tissues or organs to 271 counteract the effects of drought. Citric acid was the only acid affected by the interaction 272 between cultivar, water treatments and elicitation with MeJA (Table 1). The differential 273 osmotic adjustments observed among cultivars warrants further research aiming to obtain new 274 strawberry cultivars with increase resistance to drought. 
In terms of the leaves antioxidant capacity (AC), cultivar was the main source of

276 variation, with cultivar $253 / 29$ having the greatest $\mathrm{AC}$ values $\left(133.5 \mathrm{mg} \mathrm{Fe} \mathrm{g}^{-1} \mathrm{DW}\right)$

277 followed by cvs. $279 / 5$ (131.8 $\left.\mathrm{mg} \mathrm{Fe}^{2+} \mathrm{g}^{-1} \mathrm{DW}\right)$ and $279 / 4$ (111.2 $\left.\mathrm{mg} \mathrm{Fe}^{2+} \mathrm{g}^{-1} \mathrm{DW}\right)$,

278 respectively. Whereas none of the treatments alone had a significant effect on leaf AC, the

279 interaction between water treatment and MeJA was significant. In plants kept at or near field

280 capacity, elicitation with MeJA resulted in fairly similar AC values, whereas greater values

281 were observed in plants subjected to DI conditions (Figure 3). This result is of particular

282 interest since MeJA may partly alleviate drought stress by increasing the capacity of the plant

283 to scavenge free radicals and thus limiting the oxidative stress.

\section{$284 \quad 3.3$ Fruit biochemical changes}

High variability in the sugar concentration was observed between fruit from different

cultivars but overall values were in the range of those reported by others (Terry et al., 2007a;

287 Giné Bordonaba and Terry, 2009; Giné Bordonaba and Terry, 2010; Crespo et al., 2010).

288 Fruit from 279/4 and 279/5 had $c a$. 1.2-fold greater glucose and fructose concentrations than

289 that of $253 / 29$. Greater fructose or glucose content in these cultivars may be related to greater

290 activity of some sugar mobilising enzymes (Khelil et al., 2007) or may be just a characteric

291 trait associated to greater drought tolerance. Sucrose concentrations were greater in cultivar

292 279/5 (254.6 $\left.\mathrm{mg} \mathrm{g}^{-1} \mathrm{DW}\right)$ followed by 253/29 (240.4 $\left.\mathrm{mg} \mathrm{g}^{-1} \mathrm{DW}\right)$ and 279/4 (203.9 $\mathrm{mg} \mathrm{g}^{-1}$

293 DW). None of the treatments applied had a marked effect on fruit sugar concentration. A

294 significant interaction between MeJA, irrigation treatments and cultivar was only observed for 295 glucose concentrations whereby DI resulted in lower glucose content only for fruit from cv. $296279 / 5$. MeJA minimised the differences in glucose content of fruit receiving different amounts 297 of water. In agreement with these results, the response of strawberry plants to DI conditions 
applied at earlier development stages resulted in different sugar concentrations depending on

299 the cultivar (Giné Bordonaba and Terry, 2010). In other fruit, it has already been

300 demonstrated that DI, unless applied during the major sugar-accumulation period, does not

301 alter final sugar content (Barry et al., 2004). Therefore, the greater extent of DI treatments on

302 strawberry sugars as described in earlier works (Terry et al., 2007a; Giné Bordonaba and

303 Terry, 2010) may either be genotypically regulated or associated to initiating drought

304 conditions at earlier fruit developmental stages (Table 2). Future studies should clarify the

305 specific effect of applying DI conditions at different phenological stages on the final fruit

306 composition of a range of cultivars. Wang et al. (2008) found that preharvest application of

307 MeJA resulted in higher soluble solid content and lower titratable acidity of three blackberry

308 cultivars and similar findings were earlier reported by Wang and Zeng (2005) on raspberries.

309 Despite sugar content not always being well correlated with soluble solids measurements in

310 strawberry fruit (Giné Bordonaba and Terry, 2009), the results presented herein demonstrate

311 the differential effect of preharvest application of MeJA combined with full or deficit

312 irrigation on sugar concentrations of strawberry fruit (Table 2).

Fruit AsA content was not affected by the conditions imposed in this study except for

314 some cultivar differences. In agreement, earlier works (Giné Bordonaba and Terry, 2010)

315 found AsA to be either higher, lower or not affected in plants submitted to drought stress

316 depending on the cultivar. Besides, high variability in the AsA content among different

317 strawberry cultivars has been extensively described in the literature (Tulipani et al., 2008;

318 Giné Bordonaba and Terry, 2009; Giné Bordonaba and Terry, 2010; Crespo et al., 2010). AsA

319 concentration in fruit from cultivar $253 / 29\left(17.1 \mathrm{mg} \mathrm{g}^{-1} \mathrm{DW}\right)$ was 2.3 - or 1.5 -fold higher than

320 that for fruit from cvs. $279 / 4\left(7.3 \mathrm{mg} \mathrm{g}^{-1} \mathrm{DW}\right)$ and $279 / 5\left(11.7 \mathrm{mg} \mathrm{g}^{-1} \mathrm{DW}\right)$, respectively.

321 Elicitation with MeJA did not induce significant changes in fruit AsA concentrations and 
322 hence is in agreement with studies conducted on other horticultural crops (Pérez-Balibrea et

323 al., 2011). In contrast, citric acid was quite similar among cultivars (56 mg g $\mathrm{g}^{-1} \mathrm{DW}$ ) but

324 significantly affected by deficit irrigation or MeJA. Plants subjected to drought stress resulted

325 in either higher or lower citric acid content depending on the cultivar which corroborates the

326 genotype-specific response to reduced water supply reported by Giné Bordonaba and Terry

327 (2010). Preharvest foliar application of MeJA resulted in fruit with greater citric acid content

328 (60.2 $\left.\mathrm{mg} \mathrm{g}^{-1} \mathrm{DW}\right)$ if compared to fruit from non-treated plants $\left(51.1 \mathrm{mg} \mathrm{g}^{-1} \mathrm{DW}\right)$ whilst

329 opposite results were observed by Wang and Zheng (2005) in raspberries. The concentration

330 of malic acid was affected by differences in genotypes as well as the interactions between

331 irrigation and cultivar or between the different preharvest treatments applied fruit (Table 2),

332 yet no clear conclusions may be drawn.

Four different anthocyanins, namely cyanidin-3-glucoside (Cya-3-gluc), pelargonidin-

334 3-glucoside (Pg-3-gluc) and two pg-derivatives, were identified in the present study according

335 to their retention time, UV spectra and comparison with standards (Giné Bordonaba et al., 336 2011), although their concentration strongly depended on the cultivar and treatment applied.

337 Fruit from cultivar 253/29 were characterised by the presence of these four pigments whereas 338 fruit from cultivars 279/4 and 279/5 lacked the pg-derivative 2 (Table 3). Significant 339 differences between cultivars were observed for each individual anthocyanin hence 340 corroborating the strong influence of genetic background in determining anthocyanin content 341 of strawberry fruit (Carbone et al., 2009; Crespo et al., 2010). In detail, fruit from cultivar 342 279/5 had ca. 2-fold greater pg-3-gluc concentrations than that of fruit from cultivars 279/4 343 and 253/29. DI had little effect on the anthocyanin concentrations of the different cultivars 344 investigated. In contrast, earlier works (Terry et al., 2007) found anthocyanin concentrations 345 to be greater in fruit from plants (cv. Elsanta) that received less water. In the above- 
mentioned study deficit irrigation was applied at flower initiation and hence it may be

347 possible to speculate that even though anthocyanin accumulation occurs during later

348 developmental stages (Carbone et al., 2009) the enhanced synthesis of these pigments as a

349 result of drought stress may be up-regulated or triggered at much earlier development stages

350 (i.e. from flower initiation up to green-stage). In addition, results from the present study

351 revealed the differential effect that water deficit irrigation may have on strawberry

352 anthocyanins of different cultivars as also observed for other metabolites herein and

353 elsewhere (Giné Bordonaba and Terry, 2010). Preharvest elicitation with MeJA has been

354 shown to enhance anthocyanin concentrations in berries (Pérez et al., 1997; Wang and Zheng,

355 2005; Wang et al., 2009) and other fruit (Rudell et al., 2008). In a recent study using Fragaria

356 Chiloensis ripened in vitro, MeJA $(10$ and $100 \mu \mathrm{M})$ was shown to induce ripening through its

357 involvement of anthocyanin accumulation, cell wall degradation and the biosynthesis of

358 ethylene (Concha et al., 2013). In the present study, anthocyanin concentration of the fruit

359 was also positively influenced by preharvest treatment with MeJA; this was especially

360 noticeable in fruit from cv. 279/5 where the concentration of cya-3-gluc, Pg-3-gluc and Pg-

361 derivatives was 1.8, 2.7 and 1.8-fold greater, respectively, in MeJA-treated plants if compared

362 to control. The enhanced synthesis of anthocyanins following elicitation with MeJA has been

363 related to the direct effect of this hormone on plant secondary metabolism and especially on

364 the activation of the enzyme phenylalanine ammonia lyase (Gundlach et al., 1992; Concha et 365 al., 2013).

\section{CONCLUSIONS}


metabolism is one mechanism which in turn depends not only on the cultivar but also on the

370 plant organ (namely leaf and/or fruit). Accordingly, this is the first report describing changes

371 in the major sugar and organic acids in both fruit and leaves of strawberry plants subjected to

372 deficit irrigation. Elicitation with MeJA, under the conditions described in this study, had a

373 minimal effect on plant growth and some morphological traits (fruit weight, runners biomass,

374 dry matter of leaves and fruit, etc.) which in turn was cultivar dependent. Nonetheless, MeJA

375 resulted in increased fructose content of DI-treated leaves and minimised the differences in

376 glucose content between fruit from different water treatments. Under the conditions

377 investigated, MeJA did not alter fruit ripening (sugar and acid accumulation) but had a 378 pronounced effect on the plant secondary metabolism by increasing the synthesis and 379 accumulation of the main strawberry anthocyanin (Pg-3-gluc) in cultivar 279/5. In less 380 drought-tolerant cultivars (namely 253/29), the negative effects of DI on fruit size were not 381 mitigated and anthocyanin accumulation was not enhanced by elicitation with MeJA. Further 382 studies are encouraged to investigate greater doses of this natural hormone or more continued 383 applications aiming to further understand the relationship between drought resistance and 384 MeJA in strawberry plants.

386 AKNOWLEDGEMENTS

The authors thank the Horticultural Development Company (CP 43) and 388 GlaxoSmithKline for funding. Redeva, formerly the Summer Fruit Company, Total Berry 389 (UK) is gratefully acknowledge for supplying the plants. 


\section{REFERENCES}

400 401

402

403

404

405

406

407

408

409

410

411

412

413

414

415

416

417

418

419

420

421

422

423

Ayala-Zavala, J.F., Wang, S.Y., Wang, C.Y., Gonzalez-Aguilar, G.A., 2005. Methyl jasmonate in conjunction with ethanol treatment increases antioxidant capacity, volatile compounds and postharvest life of strawberry fruit. Eur. Food Res. Technol. 221, 731-738.

Barry, G.H., Castle, W.S., Davies, F.S., 2004. Rootstocks and plant water relations affect sugar accumulation of citrus fruit via osmotic adjustment. J. Amer. Soc. Hort. Sci. 129, 881-889.

Blatt, C.R., 1984. Irrigation, mulch, and double row planting related to fruit size and yield of Bounty strawberry. HortScience 19, 826-827.

Carbone, F., Preuss, A., De Vos, R.C.H., D'amico, E., Perrotta, G., Bovy, A.G., Martens, S. and Rosati, C., 2009. Developmental, genetic and environmental factors affect the expression of flavonoid genes, enzymes and metabolites in strawberry fruit. Plant Cell Environ. 32, 1117-1131.

Cheong, J.J., Choi, Y.D., 2003. Methyl jasmonate as a vital substance in plants. Trends Genet. 19, 409-413.

Concha, C.M., Figueroa, N.E., Poblete, L.A., Oñate, F.A., Schwab, W. and Figueroa, C.R. Methyl jasmonate treatment induces changes in fruit ripening by modifying the expression of several ripening genes in Fragaria chiloensis fruit. Plant Physiol. Biochem. 70, 433-444.

Crespo, P., Giné Bordonaba, J., Terry, L.A., Carlen, C., 2010. Characterisation of major taste and health-related compounds of four strawberry genotypes grown at different Swiss production sites. Food Chem. 122, 16-24.

Grant, O.M., Johnson, A.W., Davies, M.J., James, C.M., Simpson, D.W., 2010. Physiological and morpholical diversity of cultivated strawberry (Fragaria $\mathrm{x}$ ananassa) in response to water deficit. Environ. Exp. Bot. 68, 264-272.

Grant, O.M., Davies, M.J., Johnson, A.W., Simpson, D.W., 2012. Physiological and growth responses to water deficit in cultivated strawberry (Fragaria x ananassa) and in one of its progenitors, Fragaria chiloensis. Environ. Exp. Bot. 83, 23-32.

Giné Bordonaba, J., Terry, L.A., 2009. Development of a glucose biosensor for rapid assessment of strawberry quality: Relationship between biosensor response and fruit composition. J. Agric Food Chem. 57. 8220-8226. 
424

425

426

427

428

429

430

431

432

433

434

435

436

437

438

439

440

441

442

443

444

445

446

447

448

449

450

451

452

453

454

455

456

Giné Bordonaba, J., Terry, L.A., 2010. Manipulating the taste-related composition of strawberry fruit (Fragaria x ananassa) from different cultivars using deficit irrigation. Food Chem. 122, 1020-1026.

Giné Bordonaba, J., Terry, L.A., 2011a. Strawberry. In: Terry, L.A. (Ed.) Health-promoting properties of fruit and vegetables. CABI, Wallingford, Oxfordshire, UK, pp. 291-320.

Giné Bordonaba, J., Crespo, P., Terry, L.A., 2011b. A new acetonitrile-free mobile phase for HPLC-DAD determination of individual anthocyanins in blackcurrant and strawberry fruit: a comparison and validation study. Food Chem. 129, 1265-1273.

Giné Bordonaba, J., Terry, L.A., 2012. Electrochemical behaviour of polyphenol rich fruit juices using disposable screen-printed electrodes: Towards a rapid sensor for antioxidant capacity and individual antioxidants. Talanta, 90, 38-45.

Gundlach, H., Müller, M.J., Kutchan, T.M., Zenk, M.H., 1992. Jasmonic acid is a signal transducer in elicitor-induced plant cell cultures. Proc. Natl. Acad. Sci. USA, 89, 2389-2393.

Hassanein, R.A., Hassanein, A.A., El-din, A.B., Salama, M., Hashem, H.A., 2009. Role of jasmonic acid and abscisic acid treatments in alleviating the adverse effects of drought stress and regulating trypsin inhibitor production in soybean plant. Aust. J. Bas. Appl. Sci. 3, 904-919.

Horton, R.F., 1991. Methyl jasmonate and transpiration in barley. Plant Physiol. 96, 13761378.

Jahangir, M., Abdel-Farid, I. B., Kim, H. K., Choi, Y. H., Verpoorte, R., 2009. Healthy and unhealthy plants: The effect of stress on the metabolism of brassicaceae. Environ. Exp. Bot. 67, 23-33.

Keutgen, A. J., Pawelzik, E., 2008. Quality and nutritional value of strawberry fruit under long term salt stress. Food Chem. 107, 1413-1420.

Krüger, E., Schmidt, G. and Brückner, U., 1999. Scheduling strawberry irrigation based upon tensiometer measurement and a climatic water balance model. Sci. Hortic. 81(4), 409424.

Liu, F., Savić, S., Jensen, C. R., Shahnazari, A., Jacobsen, S. E., Stiki, R., Andersen, M.N., 2007. Water relations and yield of lysimeter-grown strawberries under limited irrigation. Sci. Hortic. 111, 128-132. 
Manganaris, G.A., Goulas, V., Vicente, A.R. and Terry, L.A. 2013. Berry antioxidants: small fruits providing large benefits. J Sci. Food Agric. 94, 825-833.

Maksymiec, W., Krupa, Z., 2007. Effects of methyl jasmonate and excess copper on root and leaf growth. Biol. Plantarum. 51, 322-326.

Pérez, A.G., Sanz, C., Olías, R., Olías, J.M., 1997. Effect of methyl jasmonate on in vitro strawberry ripening. J. Agric. Food Chem. 45, 3733-3737.

Pérez-Balibrea, S., Moreno, D.A., García-Viguera, C., 2011. Improving the phytochemical composition of broccoli sprouts by elicitation. Food Chem. 129, 35-44.

Ravnikar, M., Vilhar, B., Gogala, N., 1992. Stimulatory effects of jasmonic acido in potato stem node and protopast culture. J. Pant Growth Regul. 11, 29-33.

Rohwer, C.L., Erwin, J.E., 2008. Horticultural applications of jasmonates: a review. J. Hortic. Sci. Biotech. 83, 283-304.

Rudell, D.R., Mattheis, J. P., 2008. Synergism exists between ethylene and methyl jasmonate in artificial light-induced pigment enhancement of 'Fuji' apple fruit peel. Postharv. Biol. Technol. 47, 136-140.

Savić, S., Stiki, R., Radovi, B.V., Bogievi, B., Jovanovi, Z. Šukalovi, V.H., 2008. Comparative effects of regulated deficit irrigation (RDI) and partial root-zone drying (PRD) on growth and cell wall peroxidase activity in tomato fruit. Sci. Hortic. 117, 15 20.

Serrano, L., Carbonell, X., Savé, R., Marfà, O., Peñuelas, J., 1992. Effects of irrigation regimes on the yield and water use of strawberry. Irrig. Sci., 13, 45-48.

Staswick, P. E., Su, W., Howell, S. H., 1992. Methyl jasmonate inhibition of root growth and induction of a leaf protein are decreased in an arabidopsis thaliana mutant. Proc. Natl. Acad. Sci. USA, 89, 6837-6840.

Terry, L.A. and Joyce, D.C. 2004. Influence of growing condition and associated variable efficacy of acibenzolar in suppression of Botrytis cinerea on strawberry fruit. $A d v$. Straw. Res. 23, 11-19

Terry, L.A., Joyce, D.C., Adikaram, N.K.B., Khambay, B.P.S., 2004. Preformed antifungal compounds in strawberry fruit and flower tissues. Postharv. Biol. Technol. 31, 201212. 
Terry, L.A., Chope, G.A., Giné Bordonaba, J., 2007a. Effect of water deficit irrigation and inoculation with Botrytis cinerea on strawberry (Fragaria $x$ ananassa) fruit quality. $J$. Agric. Food Chem. 55, 10812-10819.

Terry, L.A., Ilkenhans, T., Poulston, S., Rowsell, L., Smith, A.W.J., 2007b. Development of new palladium-promoted ethylene scavenger. Postharv. Biol. Technol. 45, 214-220.

Tulipani, S., Mezzetti, B., Capocasa, F., Bompadre, S., Beekwilder, J., De Vos, C.H.R., Capanoglu, E., Bovy, A. Battino, M., 2008. Antioxidants, phenolic compounds, and nutritional quality of different strawberry genotypes. J. Agric. Food Chem. 56, 696704.

Wang, S. Y., 1999. Methyl jasmonate reduces water stress in strawberry. J. Plant Growth Regul. 18, 127-134.

Wang, C.Y., 2003. Maintaining postharvest quality of raspberries with natural volatile compounds. Int. J. Food Sci. Technol. 38, 869-875.

Wang, S.Y., Zheng, W., 2005. Preharvest application of methyl jasmonate increase fruit quality and antioxidant capacity in raspberries. Int. J. Food Sci. Technol. 40, 187-195.

Wang, S.Y., Bowman, L., Ding, M., 2008. Methyl jasmonate enhances antioxidant capacity and flavonoid content in blackberries (Rubus sp.) and promotes antiproliferation of human cancer cells. Food Chem. 107, 1261-1269.

Wang, K., Jin, P., Cao, S., Shang, H., Yang, Z., Zheng, Y., 2009. Methyl jasmonate reduces decay and enhances antioxidant capacity in Chinese bayberries. J. Agric. Food Chem. $57,5809-5815$.

Wolfe, K.L., Kang, X., He, X., Dong, M., Zhang, Q., Liu, R.H., 2008. Cellular antioxidant activity of common fruit. J. Agric Food Chem. 56, 8418-8426. 
522 Table captions:

523 Table 1: Sugar concentration $\left(\mathrm{mg} \mathrm{g}^{-1} \mathrm{DW}\right)$ in strawberry secondary fruit and leaves of three 524 different cultivars in response to drought and/or elicitation with 0 (-MJ) or $0.1 \mathrm{mM}$ MeJA $525(+\mathrm{MJ})$.

526 Table 2: Organic acid concentration $\left(\mathrm{mg} \mathrm{g}^{-1} \mathrm{DW}\right)$ in strawberry secondary fruit and leaves of 527 three different cultivars in response to drought and/or elicitation with 0 (-MJ) or $0.1 \mathrm{mM}$ 528 MeJA (+MJ).

529 Table 3: Concentration of individual anthocyanins (cyanidin-3-glucoside (Cya-3-gluc), 530 pelargonidin-3-glucoside (Pg-3-gluc) and pelargonidin derivatives (Pg-deriv 1 and 2) in 531 strawberry secondary fruit from three different cultivars in response to drought and/or 532 elicitation with $0(-\mathrm{MJ})$ or $0.1 \mathrm{mM}$ MeJA (+MJ).

\section{Figure captions:}

535 Figure 1: Average water conductivity of the growing media in plants from three strawberry 536 pre-commercial cultivars (A: 253/29; B: 279/4; C: 279/5) grown under deficit irrigation (DI;

$\left.53750 \mathrm{~mL} \mathrm{day}^{-1}\right)$ or full irrigation $\left(\mathrm{CT} ; 200 \mathrm{~mL} \mathrm{day}^{-1}\right)$ and treated with 0 or $0.1 \mathrm{mM}$ foliar 538 application of MeJA. (D) Dynamic changes in soil water content (expressed as soil 539 conductivity) of the growing media grown under deficit irrigation $\left(50 \mathrm{~mL}\right.$ day $^{-1}$; empty 
540 symbols) or full irrigation $\left(200 \mathrm{~mL} \mathrm{day}^{-1}\right.$; full symbols) and treated with 0 (round) or $0.1 \mathrm{mM}$ 541 (triangle) foliar application of MeJA. Error bar depicts LSD values $(\mathrm{p}<0.05)$ for the 542 interaction between water treatment*MeJA (A, B and C) or water treatment*MeJA*day (D).

543 Figure 2: Runners biomass $\left(\mathrm{g} \mathrm{plant}^{-1}\right)$ and weight characteristics of fruit and leaves from three 544 strawberry pre-commercial cultivars grown under deficit irrigation (DI; $50 \mathrm{~mL}$ day $^{-1}$ ) or full 545 irrigation $\left(\mathrm{CI} ; 200 \mathrm{~mL} \mathrm{day}^{-1}\right)$ and treated with $0(\mathrm{MJ}-)$ or $0.1 \mathrm{mM}$ foliar application of $546 \operatorname{MeJA}(+\mathrm{MJ})$. Error bars depict standard deviation for $\mathrm{n}=3$.

547 Figure 3: Antioxidant capacity $\left(\mathrm{mg} \mathrm{Fe}^{2+} \mathrm{g}^{-1} \mathrm{DW}\right)$ of strawberry leaves from three strawberry 548 pre-commercial cultivars grown under deficit irrigation (DI; $50 \mathrm{~mL} \mathrm{day}^{-1}$ ) or full irrigation $549\left(\mathrm{CI} ; 200 \mathrm{~mL} \mathrm{day}^{-1}\right)$ and treated with $0(\mathrm{MJ}-)$ or $0.1 \mathrm{mM}$ foliar application of MeJA (+MJ). 550 Error bars depict standard deviation for $\mathrm{n}=3$. 
Table 1: Sugar and organic acid concentration $\left(\mathrm{mg} \mathrm{g}^{-1} \mathrm{DW}\right)$ in leaves of strawberry plants from three different pre-commercial cultivars in response to drought and/or elicitation with 0 (-MJ) or $0.1 \mathrm{mM} \mathrm{MeJA}(+\mathrm{MJ})$.

\begin{tabular}{|c|c|c|c|c|c|c|c|c|c|c|c|c|c|}
\hline \multirow[b]{2}{*}{$\mathrm{Cv}$} & \multirow[b]{2}{*}{ Irrigation } & \multicolumn{2}{|c|}{ Fructose } & \multicolumn{2}{|c|}{ Glucose } & \multicolumn{2}{|c|}{ Sucrose } & \multicolumn{2}{|c|}{ Ascorbic } & \multicolumn{2}{|c|}{ Citric } & \multicolumn{2}{|c|}{ Malic } \\
\hline & & $-\mathrm{MJ}$ & $+\mathrm{MJ}$ & -MJ & $+\mathrm{MJ}$ & -MJ & $+\mathrm{MJ}$ & $-\mathrm{MJ}$ & $+\mathrm{MJ}$ & $-\mathrm{MJ}$ & $+\mathrm{MJ}$ & -MJ & $+\mathrm{MJ}$ \\
\hline \multirow[t]{2}{*}{$253 / 29$} & 50 & 35.5 & 42.3 & 41.3 & 48.7 & 59.3 & 64.3 & 1.7 & 1.5 & 11.3 & 10.5 & 27.2 & 25.5 \\
\hline & 200 & 36.9 & 33 & 51.9 & 41.2 & 65.1 & 48.5 & 1.3 & 1.1 & 8.4 & 8.0 & 24.6 & 15.8 \\
\hline \multirow[t]{2}{*}{$279 / 4$} & 50 & 45.1 & 55.9 & 51.8 & 65.2 & 82.4 & 75.9 & 1.1 & 1.4 & 10.9 & 7.6 & 28.0 & 32.9 \\
\hline & 200 & 32.4 & 36.1 & 41.4 & 45.1 & 66.8 & 75.6 & 1.0 & 1.0 & 9.0 & 10.8 & 26.3 & 20.1 \\
\hline \multirow[t]{2}{*}{$279 / 5$} & 50 & 51.4 & 69 & 53.4 & 70.3 & 84.7 & 87.6 & 2.8 & 2.0 & 12.2 & 16.0 & 16.6 & 19.5 \\
\hline & 200 & 52.8 & 50.3 & 56.3 & 56.4 & 82.3 & 87.2 & 1.2 & 1.3 & 16.4 & 12.4 & 28.9 & 27.1 \\
\hline \multicolumn{2}{|l|}{$\mathrm{LSD}_{\mathrm{cv}}$} & \multicolumn{2}{|c|}{7.53} & \multicolumn{2}{|c|}{3.61} & \multicolumn{2}{|c|}{10.22} & \multicolumn{2}{|c|}{0.39} & \multicolumn{2}{|c|}{2.51} & \multicolumn{2}{|c|}{7.50} \\
\hline \multicolumn{2}{|c|}{$\mathrm{LSD}_{\mathrm{cv} * \text { irrigation }}$} & \multicolumn{2}{|c|}{10.64} & \multicolumn{2}{|c|}{10.56} & \multicolumn{2}{|c|}{14.46} & \multicolumn{2}{|c|}{0.55} & \multicolumn{2}{|c|}{3.56} & \multicolumn{2}{|c|}{10.61} \\
\hline \multicolumn{2}{|c|}{$\mathrm{LSD}_{\mathrm{Cv} v \text { irrigation*MeJA }}$} & \multicolumn{2}{|c|}{15.05} & \multicolumn{2}{|c|}{15.00} & \multicolumn{2}{|c|}{20.45} & \multicolumn{2}{|c|}{0.78} & \multicolumn{2}{|c|}{5.04} & \multicolumn{2}{|c|}{14.00} \\
\hline
\end{tabular}


Table 2: Sugar and organic acid concentration $\left(\mathrm{mg} \mathrm{g}^{-1} \mathrm{DW}\right)$ in strawberry secondary fruit of three different pre-commercial cultivars in response to drought and/or elicitation with $0(-\mathrm{MJ})$ or $0.1 \mathrm{mM} \mathrm{MeJA}(+\mathrm{MJ})$.

\begin{tabular}{|c|c|c|c|c|c|c|c|c|c|c|c|c|c|}
\hline \multirow[b]{2}{*}{$\mathrm{Cv}$} & \multirow[b]{2}{*}{ Irrigation } & \multicolumn{2}{|c|}{ Fructose } & \multirow{2}{*}{$\begin{array}{r}\text { Glucose } \\
-\mathrm{MJ}\end{array}$} & \multicolumn{3}{|c|}{ Sucrose } & \multirow{2}{*}{$\begin{array}{r}\text { Ascorbic } \\
-\mathrm{MJ}\end{array}$} & \multicolumn{2}{|r|}{ Citric } & \multicolumn{3}{|c|}{ Malic } \\
\hline & & -MJ & $+\mathrm{MJ}$ & & $+\mathrm{MJ}$ & -MJ & $+\mathrm{MJ}$ & & $+\mathrm{MJ}$ & $-\mathrm{MJ}$ & $+\mathrm{MJ}$ & -MJ & $+\mathrm{MJ}$ \\
\hline \multirow[t]{2}{*}{$253 / 29$} & 50 & 189.5 & 191.2 & 183.6 & 190.2 & 213.5 & 262.4 & 15.6 & 25.5 & 62.4 & 82.4 & 8.3 & 14.1 \\
\hline & 200 & 178.9 & 191.3 & 174.4 & 185.3 & 264.3 & 221.4 & 16.6 & 10.5 & 56.6 & 44.7 & 13.1 & 10.5 \\
\hline \multirow[t]{2}{*}{$279 / 4$} & 50 & 209.2 & 201.3 & 213.9 & 194.8 & 210.7 & 193.1 & 5.4 & 5.0 & 42.7 & 50.1 & 6.1 & 6.6 \\
\hline & 200 & 204.2 & 211.4 & 206.7 & 210.2 & 210 & 201.9 & 8.5 & 10.5 & 54.9 & 60.9 & 13.9 & 8.5 \\
\hline \multirow[t]{2}{*}{$279 / 5$} & 50 & 248 & 226.4 & 181.5 & 228.8 & 249.8 & 232.7 & 12.5 & 15.0 & 59.4 & 68.1 & 16.9 & 13.0 \\
\hline & 200 & 216.5 & 209.4 & 218.9 & 204.4 & 284.3 & 251.6 & 5.5 & 13.9 & 34.8 & 54.9 & 13.6 & 11.6 \\
\hline \multicolumn{2}{|l|}{$\operatorname{LSD}_{\mathrm{cv}}$} & \multicolumn{2}{|c|}{24.14} & \multicolumn{2}{|c|}{15.34} & \multicolumn{2}{|c|}{25.61} & \multicolumn{2}{|c|}{5.14} & \multicolumn{2}{|c|}{9.54} & \multicolumn{2}{|l|}{2.59} \\
\hline \multicolumn{2}{|c|}{$\mathrm{LSD}_{\mathrm{cv} * \text { irrigation }}$} & \multicolumn{2}{|c|}{30.13} & \multicolumn{2}{|c|}{21.78} & \multicolumn{2}{|c|}{36.22} & \multicolumn{2}{|c|}{7.26} & \multicolumn{2}{|c|}{13.49} & \multicolumn{2}{|l|}{3.67} \\
\hline \multicolumn{2}{|c|}{$\mathrm{LSD}_{\mathrm{cv} * \text { irrigation*MeJA }}$} & \multicolumn{2}{|c|}{38.27} & \multicolumn{2}{|c|}{30.68} & \multicolumn{2}{|c|}{51.22} & \multicolumn{2}{|c|}{10.27} & \multicolumn{2}{|c|}{19.07} & \multicolumn{2}{|l|}{5.19} \\
\hline
\end{tabular}


Table 3: Concentration ( $\mu \mathrm{g} \mathrm{g}^{-1} \mathrm{DW}$ ) of individual anthocyanins (cyaniding-3-glucoside (Cya-3-gluc), pelargonidin-3-glucoside (Pg-3-gluc) and pelargonidin derivatives (Pg-deriv 1 and 2) in strawberry secondary fruit from three different cultivars in response to drought and/or elicitation with 0 or $0.1 \mathrm{M}$ MeJA.

\begin{tabular}{|c|c|c|c|c|c|c|c|c|c|}
\hline \multirow[b]{2}{*}{$\mathrm{Cv}$} & \multirow[b]{2}{*}{ Irrigation } & \multicolumn{2}{|c|}{ Cya-3-gluc } & \multicolumn{2}{|c|}{ Pg-3-gluc } & \multicolumn{2}{|c|}{ Pg-deriv. 1} & \multicolumn{2}{|c|}{ Pg-deriv. 2} \\
\hline & & $-\mathrm{MJ}$ & $+\mathrm{MJ}$ & $-\mathrm{MJ}$ & $+\mathrm{MJ}$ & $-\mathrm{MJ}$ & $+\mathrm{MJ}$ & $-\mathrm{MJ}$ & $+\mathrm{MJ}$ \\
\hline \multirow[t]{2}{*}{$253 / 29$} & 50 & 44.2 & 33.5 & 1559.2 & 880.2 & 148.3 & 89.8 & 377.7 & 227.2 \\
\hline & 200 & 41.4 & 33.3 & 776 & 874 & 68.1 & 94.8 & 166.6 & 237.2 \\
\hline \multirow[t]{2}{*}{$279 / 4$} & 50 & 20.1 & 30.8 & 764 & 587 & 47.5 & 42.6 & - & - \\
\hline & 200 & 23.2 & 27.9 & 1252 & 1054 & 59.7 & 58.8 & - & - \\
\hline \multirow[t]{2}{*}{$279 / 5$} & 50 & 26 & 48.3 & 1174 & 3198 & 72.4 & 132.3 & - & - \\
\hline & 200 & 22.9 & 31.5 & 890 & 2782 & 57.6 & 123.6 & - & - \\
\hline \multicolumn{2}{|c|}{$\mathrm{LSD}_{\mathrm{cv}}$} & \multicolumn{2}{|c|}{5.11} & \multicolumn{2}{|c|}{356.27} & \multicolumn{2}{|c|}{15.49} & \\
\hline \multicolumn{2}{|c|}{$\mathrm{LSD}_{\mathrm{cv} * \text { irrigation }}$} & \multicolumn{2}{|c|}{7.23} & \multicolumn{2}{|c|}{503.82} & \multicolumn{2}{|c|}{21.91} & \multicolumn{2}{|c|}{75.84} \\
\hline \multicolumn{2}{|c|}{$\mathrm{LSD}_{\mathrm{cv} * \text { irrigation*MeJA }}$} & \multicolumn{2}{|c|}{10.22} & \multicolumn{2}{|c|}{712.51} & \multicolumn{2}{|c|}{30.99} & \multicolumn{2}{|c|}{102.13} \\
\hline
\end{tabular}




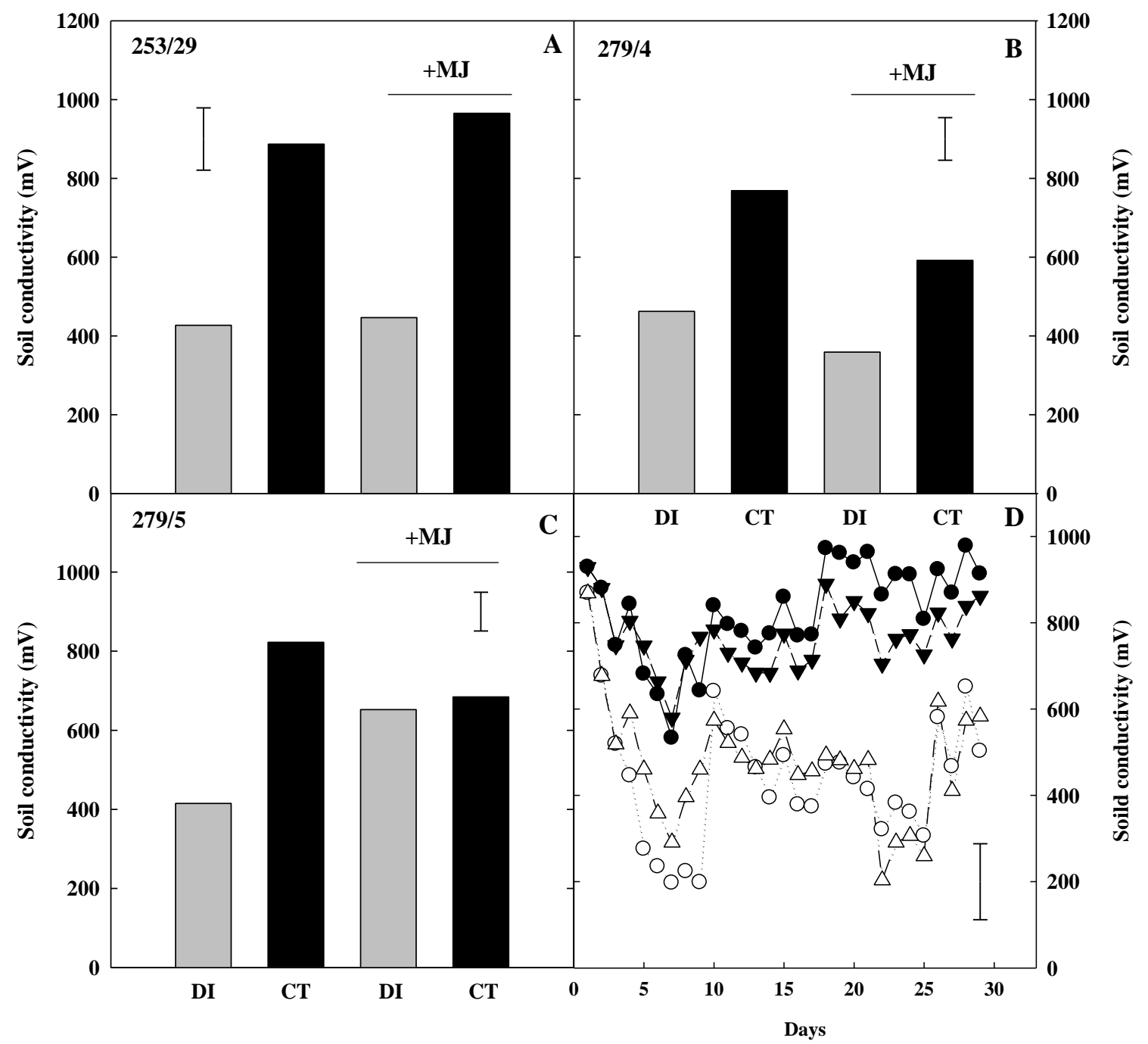

Figure 1: Giné Bordonaba and Terry 

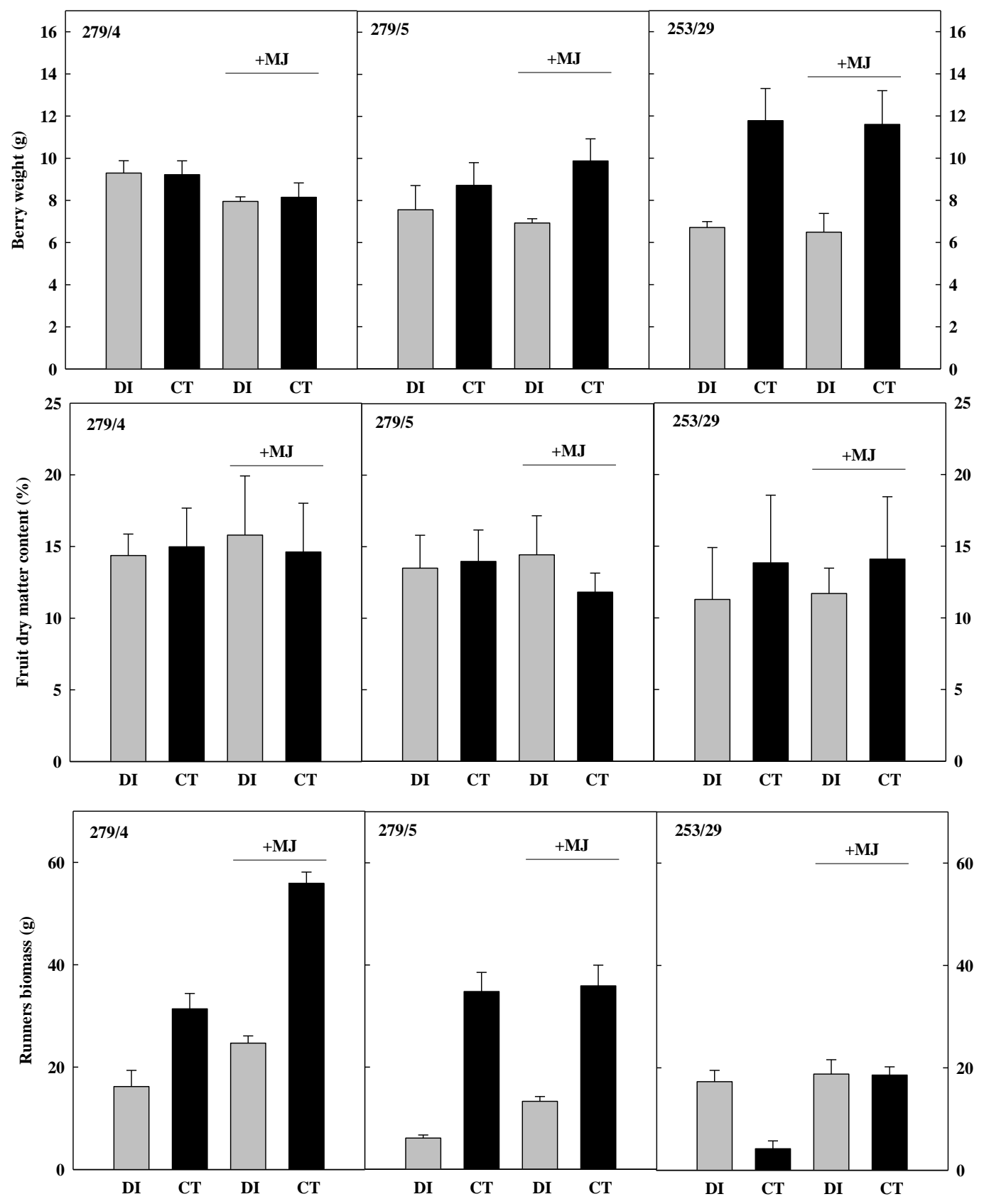

Figure 2: Giné Bordonaba and Terry 


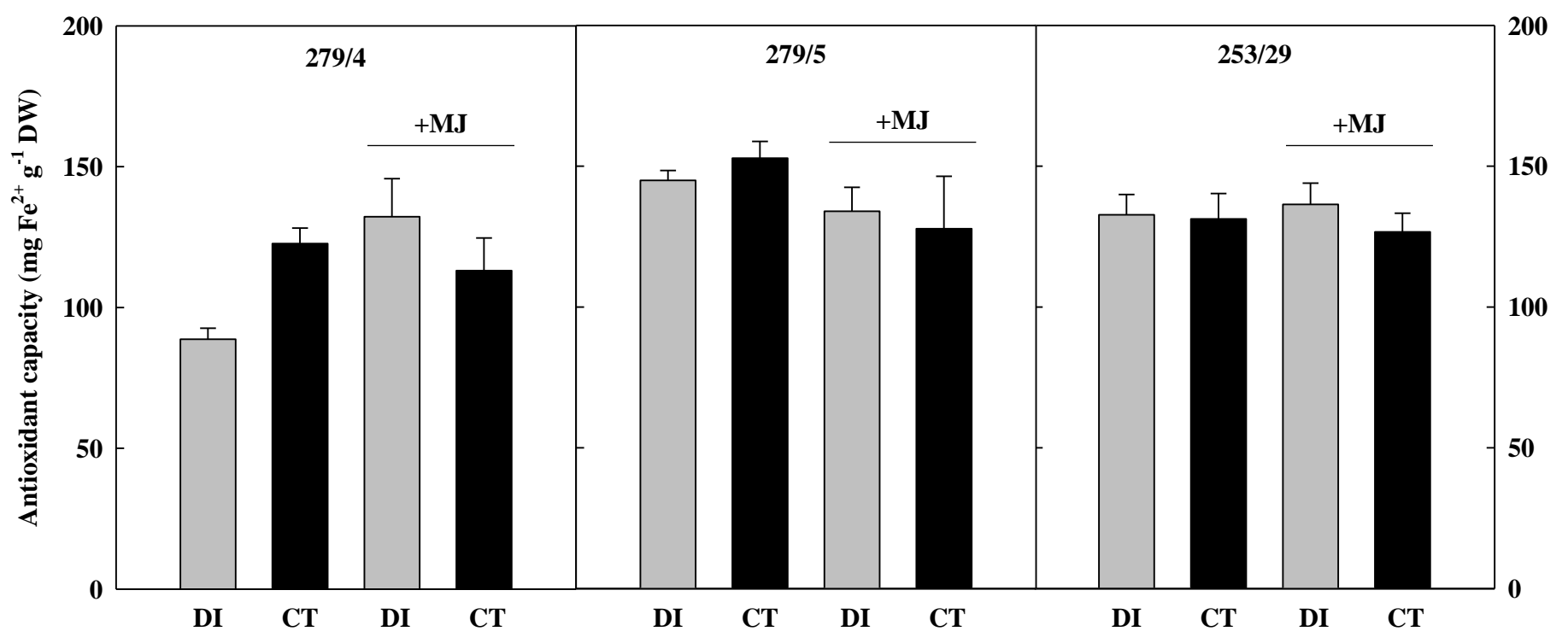

Figure 3: Giné Bordonaba and Terry 


\section{RESEARCH HIGHLIGHTS}

- The effects of deficit irrigation from green stage to ripe fruit on strawberry fruit size and quality are cultivar dependent.

- Changes in sugar and organic acids in response to drought were differently regulated in fruit than in leaves.

- Elicitation with MeJA had a minimal effect on plant growth.

- MeJA increased the concentration of pelargonidin-3-glucoside in ripe red fruit from one cultivar. 


\section{Graphical Abstract}
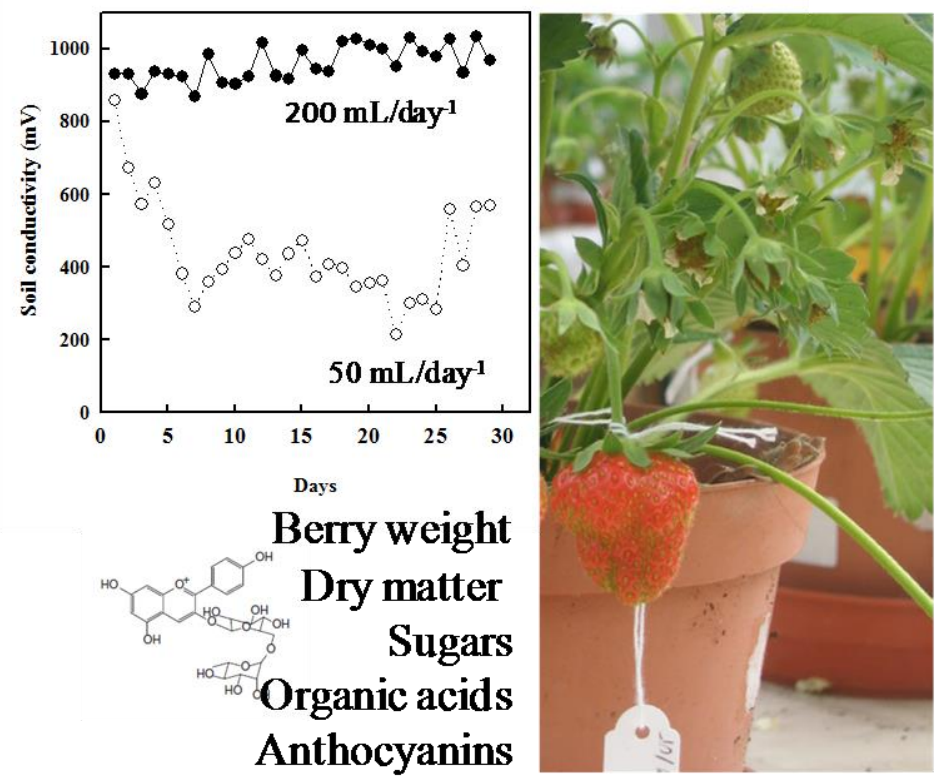

Leaf colour

Sugars

Organic acids

Antioxidant capacity

Runners biomass 